[Aus dem hygienischen Institut der Universität Bonn.]

(Damaliger Direktor: Prof. Dr. Kruse.)

\title{
Beiträge zur Methodik der Untersuchung der Bakterienflora des Säuglingsstuhles und zur Kenntnis seiner wichtigsten Bakterientypen.
}

Von

Dr. med. J. Basten.

(Hlerzu TaP. I.)

Solange man zur Untersuchung des Säuglïngsstuhles nur die gebräuchlichen aeroben bakteriologischen Züchtungsmethoden anwandte, erhielt man von seiner Flora ein falsches Bild. Erst nachdem Tissier, Moro und Finkelstein das anaerobe Verfahren und die Vorkultur in sauren Nährböden bei der Untersuchung eingeführt hatteri, gelang es, die einzelnen Arten der das Bild des Säuglingsstuhles beherrschenden grampositiven Bakterien zu isolieren. Bei den genannten und den späteren Untersuchern ${ }^{1}$ finden sich allerdings über die kulturellen Eigenschaften der grampositiven Bakterien und vor allem über ihr Mengenverhältnis zueinander sehr verschiedene Angaben. Wahrscheinlich sind diese zum großen Teil auf die ungleichen Methoden, mit denen gearbeitet wurde, zurückzuführen. Es erschien daher von Nutzen, erstens eine möglichst einfache zuverlässige Methode auszuarbeiten, nach der es möglich ist, sofort alle Arten der Bakterienflora eines Säuglingsstuhles in Reinkultur zu züchten und ihr Mengenverhältnis zueinander festzustellen, und zweitens mit dieser Methode zunächst einmal eine Reihe normaler Säuglingsstühle zu prüfen.

S. $308 \mathrm{ff}$.

1 Lit. bei Schmidt u. Strasburger, Die Fäzes des Menschen. 1910. 3. Anfl. 
Die folgenden Untersuchungen wurden im Bonner hygienischen Institut auf Anregung und unter Leitung von Prof. Kruse ausgeführt, das Material wurde der Frauenklinik entnommen. Es wurden im ganzen 40 im wesentlichen normale Stühle von Brust- und Flaschenkindern im Alter von 3 Tagen bis 4 Monaten untersucht. In den meisten Fällen wurde der Stuhl mit dem von Strasburger angegebenen Glasröhrchen entnommen. In einer großen Anzahl stammte die Probe unmittelbar aus den vor der Benutzung im Dampf sterilisierten Windeln. Ein Unterschied in der Zusammensetzung der nach beiden Methoden entnommenen Stühle lieB sich nicht feststellen, weder zeigten sich bei der letzteren Methode wesentliche Verunreinigungen, noch wurde bei der ersteren ein Fehlen bestimmter Arten festgestellt.

Wir gelangten allmählich zu folgender Versuchsordnung: 5 Ösen Stuhl werden in $1^{\mathrm{cm}}$ Bouillon zu einer Emulsion verrieben. Von der Emulsion wird zunächst ein Ausstrich gemacht, der nach Gram gefärbt und mit dünnem Fuchsin nachgefärbt wird. Mit einer Ose der Emulsion wird eine Traubenzuckeragarplatte (2 Prozent Tr.) beschickt. Sodann werden von je $0.1 \mathrm{ccm}$ der Emulsion 3 parallele Verdünnungsreihen von 10 Verdünnungen $(1: 10,1: 100,1: 1000$ usw.) in Röhrchen mit je 1 com Bouillon angelegt. Die erste Reihe dient zur Züchtung der Anaerobier. Jede Verdünnung wird in je einem Röhrchen mit $20^{\text {com }}$ flüssigem auf $40^{\circ}$ erkaltetem Traubenzuckeragar verteilt. Die 2. Reihe dient zur Züchtung der Sporenbildner. Sie wird 20 Minuten lang bei $70^{\circ}$ erhitzt und sodann' wie oben mit Traubenzuckeragar beschickt. Die 3. Reihe wird, um einen elektiven Nährboden für den Bac. acidophilus zu erhalten, mit je $10^{\text {com }} 1 / 2^{-}$bis 1 prozentiger essigsaurer Traubenzuckerbouillon beschickt.

Wir hatten in dèn ersten Versuchen die Verdünnungen in dem noch flüssigen, erkaltenden Agar selbst angelegt, gingen jedoch später zu den Bouillonverdünnungen über, da sie ein zuverlässigeres Bild von dem Mengenverhältnis der einzelnen Arten geben. Zur Züchtung der Anaerobier, insbesondere des Bac. bifidus, bewährte sich ausschließlich das Verfahren der hohen Traubenzuckeragarschicht. Auf der Platte fand stets sowohl bei Sanerstoffabsorption durch Pyrogallussäure wie bei der Verdrängung des Sauerstoffs durch Wasserstoff vermittels des Kippschen Apparates eine Uberwucherung durch die fakultativen Anaerobier: Bac. coli, aerogenes (Escherich) und Streptococcus lacticus (Kruse) statt. Besondere Schwierigkeiten bereitete es, den Bac. acidophilus in Reinkultur zu erhalten. In der von Moro als elektivem Nährboden für den Bac. acidophilus angebenen frischen Bierwürze fanden wir stets auch ein üppiges Wachstum des Streptococcus lacticus. Eine Ansäurung der Bierwürze in verschiedenen 
Graden bewährte sich ebenfalls nicht: Mit angesäuerter einfacher Bouillon kamen wir ebenso wenig zum Ziele, auch miBlangen Versuche mit der Agarplatte unter Zusatz von Säure und unter Zusatz von Säure + Traubenzucker in verschiedenen Mengen. Dagegen gelang es uns, beinahe aus allen Stühlen den Acidophilus zu züchten mit der oben erwähnten von Finkelstein und Salge angegebenen und auch von Winkler empfohlenen ( $1 / 2$ Prozent) essigsauren Traubenzuckerbouillon.

Es sei vorweg genommen, daB wir bei unserem allerdings nicht großen und auf die ersten Lebensmonate beschränkten Material weder im einfachen Ausstrichprāparat noch in den kulturellen Ergebnissen so beständige Unterschiede zwischen dem Stuhl normaler Brust- und Flaschenkinder feststellen konnten wie sie von Tissier u. a. gefunden wurden. Die Regel, daB der Bifidus für den ersteren, der Acidophilus für den letzteren charakteristisch wäre, hat also mindestens viele Ausnahmen. Es wurden nur Stühle von breiiger Konsistenz und der charakteristischen gelben Farbe zur Untersuchung verwandt. In der Mehrzahl der Fälle zeigt das Ausstrichpräparat nur grampositive Stäbchen. Ganz vereinzelt finden sich die kurzen gramnegativen an beiden Enden abgerundeten Stäbchen des Coli-Aerogenes, ebenso vereinzelt zeigen sich die ovalen, meist in Doppelform auftretenden ziemlich großen Formen des grampositiven Streptococcus lacticus. Die grampositiven Stäbchen zeigten in der Hälfte der Fälle vorwiegend die unregelmäBigen Bifidusformen: verschiedener Größe, teilweise an den Enden zugespitzt, teilweise ausgefranst, andere an den Enden kolbig verdickt, wieder andere mit kolbiger Verdickung im Leib selbst (s. Taf. I, Fig. 1). Nur vereinzelte Formen haben die Gramfarbe nur teilweise angenommen. In einem Ausstrich sahen wir nur Formen mit ausgesprochener Polfärbung an beiden Enden, während der Leib nicht gefärbt war (Form und Größe der Diphteriebazillen). In der Mehrzahl der Fälle fanden sich neben den Bifidusformen teils kürzere teils längere, gleichmäBiger geformte und gefarbte grampositive Stäbchen. In etwa 30 Prozent der Fälle übertrafen diese Stäbchen an Zahl bei weitem die Bifidusformen. Es sind dieselben Formen, die wir später in den Kulturen des Bac. acidophilus wiedersahen (s. Taf. I, Fig. 2).

Auf der Platte zeigen sich stets nach 24 Stunden die üppigen Kolonien des Coli oder Aerogenes und dazwischen die etwas mehr opaken weit kleineren Kolonien des Streptococcus lacticus. Diese beiden Arten vermißten wir in keinem Stuhl. Je dreimal sahen wir Hefepilze und Heubazillen. Dreimal zeigten sich auf der Platte die Kolonien des Staphylococcus albus, einmal Streptokokkenkolonien vom Typus des Streptococcus pyogenes. 
In der ersten zur Züchtung des Bac. bifidus bestimmten mit hohem Traubenzuckeragar beschickten Verdünnungsreihe machte sich stets bis zur dritten Verdünnung, in zwei Fällen sogar bis zur zehnten Verdūnnung, in den übrigen Fällen meist bis zur fünften oder sechsten Verdünnung nach 24 Stunden bei $37^{\circ}$ starke Gasbildung bemerkbar. Dieselbe geht aus ron den Kolonien des Coli-Aerogenes. Neben diesem zeigten sich meist bis zur dritten bis fünften Verdünnung die ovalen, manchmal bis $\mathbf{z u} 5^{\mathrm{mm}}$ im Durchmesser großen Kolonien des Streptococcus lacticus. Nach $\mathbf{3}$ bis 4 Tagen kommen dann dazwischen die kleinen weißlichen, unregelmäBigen, vielfach manlbeerartigen Kolonien des Bac. bifidus zum Vorschein. Von der 3. Verdünnung ab waren sie stets neben dem Gasbildner isolierbar, von der siebenten bis achten Verdünnung ab sahen wir in den meisten Fällen nur Bifiduskolonien und zwar stets, abgesehen von den Kolonien, die mit Bac. acidophilus verunreinigt waren, in der anaeroben Zone des Agar: Bei der Züchtung des Bac. acidophilus in Traubenzuckerbouillon sahen wir öfters Formen des Bac. bifidus meist mit Verzweigungen. Einmal, im Stuhl 37, zeigte sich hierbei ein außerordentlich starkes Wachstum des Bac. bifidus mit zahlreichen Verzweigungen und Auftreibungen durch die ganze Verdünnungsreihe der Traubenzuckerbonillon hindurch, in den schwächeren Verdünnungen mehr Acidophilus als Bifidus, in den stärkeren Verdünnungen überwucherte der letztere den ersteren jedoch erheblich. Bei der Weiterzüchtung des Bifidus aus diesem Medium trat wieder streng anaerobes Wachstum hervor. In Symbiose mit anderen Bakterien, in unserem Falle mit Acidophilus, gedeiht also der Bac. bifidus auch in lufthaltigem Nährboden.

Aus der hohen Traubenzuckeragarschicht gelingt es leicht, die Bifiduskolonien abzustechen und in anderen Nährböden weiter zu züchten. Allerdings sind sie sehr oft, wie auch oben schon angedeutet, mit Acidophilus verunreinigt. Eine Reinzüchtung in aeroben Bedingungen ist uns nicht gelungen. Am besten gedeiht er in hoher 2 prozentiger Zuckeragarschicht, ohne Unterschied bei Zusatz von Traubenzucker, Rohrzucker oder Malzzucker. Nach drei Tagen zeigen sich entlang dem ganzen Stich zusammenhängend weiße unregelmäßige Kolonien bis $1^{\mathrm{cm}}$ von der Oberfläche entfernt. Bei Zusatz von Milchzucker dagegen sahen wir nur kümmerliches Wachstum. Dieselben Ergebnisse hatten wir bei der Züchtung in anaerober 2 prozentiger Zuckerbouillon: nach drei Tagen leichte Trübung, in den folgenden Tagen Bildung von Wolken, die sich bald zu Boden senken. In einfachem Agar, einfacher Bouillon sahen wir kein, in Milch nur geringes Wachstum. Die Milch koaguliert nicht. Gasbildung war in keinem Falle festzustellen, in zuckerhaltigen Nährböden wurde in gewissem MaBe Säure gebildet. Je $10^{\mathrm{cem}}$ Nährboden von 6 ge- 
prüften Stämmen (Zuckeragar) brauchten zur Neutralisation bei Phenolphthaleinindikator im Durchschnitt bei Zusatz ron Traubenzucker: 1.2 bis 1.4 , von Robrzucker 1.0 bis 1.6 , von Malzzucker 1.5 bis $2.5 \mathrm{~cm}$ $1 / 10$-Normalnatronlauge.

Unsere Stämme waren bis zu 4 Wochen haltbar. Die im frischen Ausstrichpräparat und in frischen Kulturen relativ einfachen Formen des Bac. bifidus (s. Taf. I, Fig. 3) zeigen in den älteren Kulturen die mannigfachsten Variationen. Wir sehen hier die merkwürdigsten Verzweigungen, baumartige Gebilde mit stärkerer Färbbarkeit an den Verzweigungsstellen und keulenfôrmigen Verdickungen an den Enden (s. Taf. I, Fig. 4). Dieselben Formen sahen wir auch in der oben beschriebenen Symbiose mit Bac. acidophilus.

In der Verdünnungsreihe der essigsauren Traubenzuckerbouillon sahen wir in 90 Prozent der Fälle nach 24stündigem Verweilen im Brutschrank, allerdings nie über die sechste Verdünnung hinaus, zahlreiche Acidophilusformen neben vereinzeltem Bac. bifidus, Streptococcus lacticus und Aerogenes. Ein 72stündiger Aufenthalt im Brutschrank schädigte die übrigen Formen derart, da $B$ wir auf der ausgestrichenen Tranbenzuckeragarplatte meist eine Reinkultur von Bac. acidophilus erhielten. Die Kolonien auf der Platte zeigen nach 24 Stunden meist Stecknadelkopfgröße, haben einen glatten Rand, sind etwas erhaben und pon hellgelber Farbe. Dazwischen finden sich manchmal mehr flache Kolonien mit einem dunklen punktförmigen Zentrum und hellen geflechtartigen Ausläufern. Bei Überimpfen der runden erhabenen Kolonien auf andere Platten zeigten sich öfters die flachen, geflechtartigen Kolonien, beim Überimpfen der letzteren Art beobachteten wir vielfach das umgekehrte Verhalten. Dazwischen fanden sich Utbergänge. Im allgemeinen läßt sich sảgen, daB, je lānger der Acidophilus in der essigsauren Traubenzuckerbouillon verblieb, und. je älter die Stämme waren, desto bäufiger nachher die flachen geflechtartigen Kolonien auftraten. Auf Agar und Gelatine wächst der Acidophilus weniger gut. In anaerobem zuckerhaltigen Agar zeigt sich nach 24 Stunden entlang des ganzen Stiches sehr üppiges Wachstum bis zur Oberfläche, nach einigen Tagen trübt sich der Nährboden sehr stark, durch Säurebildung bedingt. $10^{\mathrm{cm}}$ Nährboden (Agar mit 2 Prozent Zucker) von 6 geprüften Stämmen brauchten zur Neutralisation bei Zusatz von Traubenzucker 8 bis $9.6^{\mathrm{cm}}$, von Rohrzucker 7.6 bis $9.1^{\mathrm{ccm}}$, ron Milchzucker 5.5 bis $8.1 \mathrm{~cm}$, von Malzzucker 3.0 bis $4.3 \mathrm{cem} 1 / 10^{-N o r m a l n a t r o n l a u g e . ~ I n ~ M i l c h ~ u n d ~}$ Zuckerbouillon zeigt sich spärliches Wachstum, nach 24 bis 48 Stunden gerinnt die erstere. In Zuckerbouillon tritt nach 24 Stunden durch das Bazillenwachstum Trübung auf, die sich nach einigen Tagen zu Boden setzt. 
Der Bac. acidophilus ist unbeweglich; er färbt sich gut und gleichmäBig nach Gram. In Gestalt und Form entspricht er in frischen Kulturen etwa den Typhusbazillen, nur ist er oft in geringem Maße gekrümmt (s. Taf. I, Fig. 5). In älteren Kulturen, vor allem in den oben beschriebenen geflechtartigen Kolonien, finden sich lange, vielfach verschlungene Fäden, die, je älter die Kulturen sind, um so mehr in der Dicke und Färbbarkeit variieren (s. Taf. I, Fig. 6). Verzweigungen sahen wir beim Acidophilus nie. In flüssigem Nährboden sind die Stäbchen meist kürzer und liegen vielfach in Kettenform hintereinander. Wir sahen Ketten bis zu 10 Gliedern.

Die im Stuhle des Erwachsenen regelmäBig auftretenden anaeroben, zur Gruppe der Buttersäurebazillen gehörenden Sporenbildner haben wir im Ausstrichpräparat des Säuglingsstuhles niemals gesehen. Mit der oben angegebenen Züchtungsmethode fanden wir in 40 Prozent der Fälle meist nur in der ersten Verdünnung vereinzelte scheibenförmige, streng anaerob wachsende Kolonien. Die ron uns isolierten Stämme zeigten in Agar und Zuckeragar gleich gutes streng anaerobes Wachstum bis $1^{\text {ecm }}$ von der Oberfläche entfernt. In zuckerhaltigen Nährböden tritt starke Gasbildung auf. Bei der anaeroben Züchtung von Milch ist nach 24 Stunden die Eprouvette zur Hälfte mit Gas gefüllt, die Milch hat sich gesondert in stark übelriechende bräunlich verfärbte feste Massen, die durch die Gasbildung nach oben getrieben werden, und klares Serum. In frischen Kulturen färben sich diese Bakterien gut nach Gram, bilden ziemlich dicke regelmäBige große Stäbchen und Fäden. In alten Kulturen verlieren sie sehr bald die Gramfärbbarkeit. Die isolierten Stämme stimmen mit den Kultureigenschaften des Bac. perfringens (Tissier) überein. Aus dem Umstande, daB sich ausgebildete Formen im Ausstrichpräparat niemals fanden, glauben wir schlieBen $\mathrm{zu}$ dürfen, daB sich die Kolonien nur aus den im Stuhle vorhandenen Sporen entwickeln.

Aus den vorliegenden Untersuchungen geht hervor, daB neben dem Bac. bifidus einen Hauptbestandteil der Bakterienflora des Sāuglingsstuhles bei Brust- und Flaschenkindern der Bac. acidophilus bildet. Wenn wir bei der kulturellen Züchtung auch den Bac. bifidus meist noch in der achten und neunten Verdünnung, in einigen Fällen sogar bis zur zehnten Verdünnung fanden, den Acidophilus dagegen nie über die sechste Verdünnung hinaus und in 10 Prozent der Fälle überhaupt nicht fanden, so glauben wir doch zu dem vorstehenden Schlusse und somit zu der obigen Deutung des Ausstrichpräparates berechtigt zu sein, da die zur Züchtung des Acidophilus verwandte essigsaure Traubenzuckerbouillon nur ein elektiver, aber keineswegs idealer Nährboden für ihn ist. Während die übrigen Bakterien durch den Säurezusatz nach 
72 Stunden abgetötet werden, ist der Acidophilus resistenter gegen Säure, aber keineswegs unempfindlich. Nach 10 Tagen lieB auch er sich aus der essigsauren Traubenzuckerbouillon nicht mehr weiterzüchten, während wir Stämme aus Traubenzuckeragar nach 3 Monaten noch überimpfen konnten. Es erscheint uns daher nicht gerechtfertigt, von einer Bifidusflora des Säuglingsstuhles zu reden und den Bac. acidophilus als zufälligen Nebenbefund zu betrachten.

\section{Erklärung der Abbildungen.}

(Tuf. I.)

Fig. 1. Säuglingsstuhl mit vorwiegend den unregelmäBigen Formen des Bacillas bifidus. VergröBerung: Zeiß' Ölimmersion, Okular 4.

Fig. 2. Säuglingsstuhl mit vorwiegend den regelmäBigen Formen des Bacillus acidophilus. VergröBerung: ZeiB' Ölimmersion, Okular 4.

Fig. 3. Reinkaltar (8 Tage alt) von Bacillus bifidus. VergöBerung: Zeiß' Ölimmersion, Okular 4.

Fig. 4. Reinkultur von Bacillus bifidus (4 Wochen alt). Vergrößerang: ZeiB' Olimmersion, Okular 6.

Fig. 5. Reinkultur von Bacillus acidophilus (24 Stunden alt). VergröBernng: ZeiB' Ölimmersion, Okular 6.

Fig. 6. Reinkultur von Bacillus acidophilus (4 Wochen alt). VergröBerung: Zeiß' Ölimmersion, Okular 4. 
Zeitschrift für Hygiene. Bd. LXXVII.

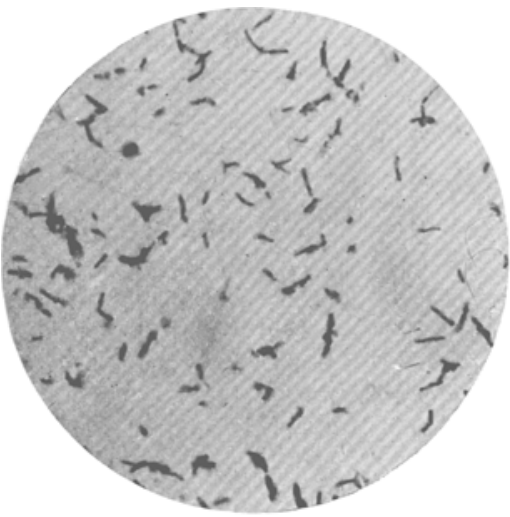

Fig. 1.

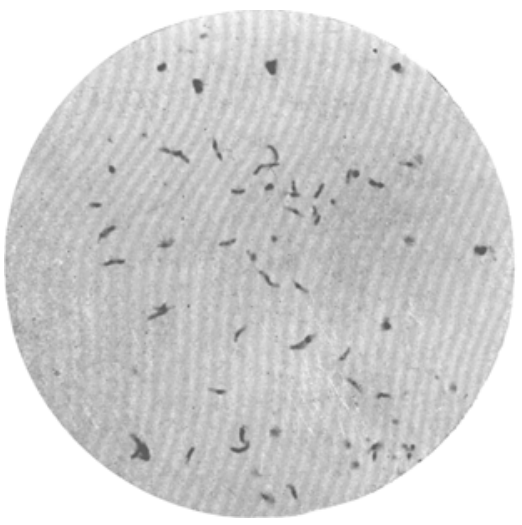

Fig. 3.

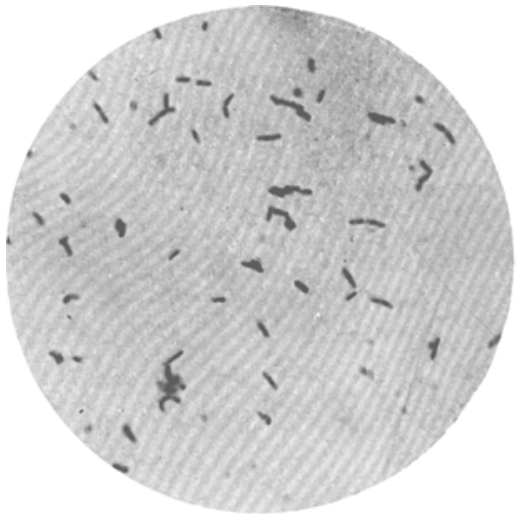

Fig. 5.

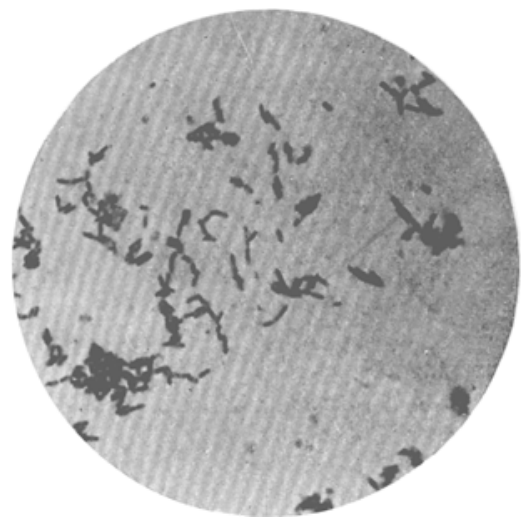

Fig. 2 .

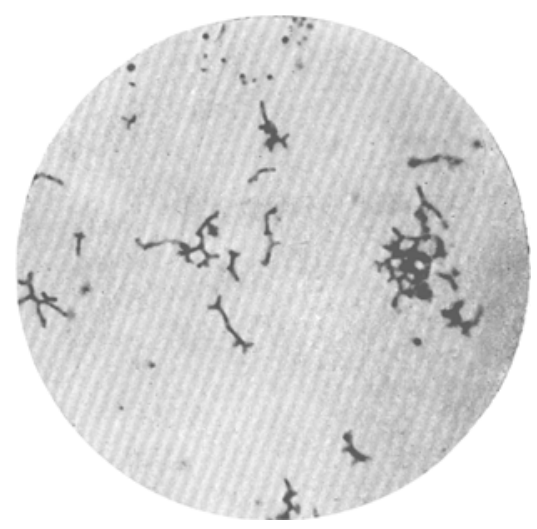

Fig. 4 .

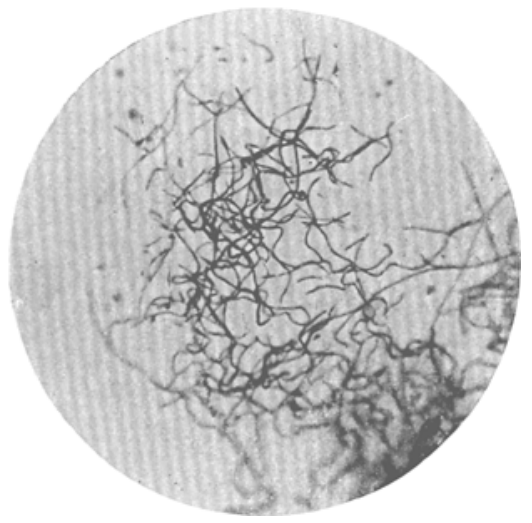

Fig. 6 . 